\title{
Study on Peer Scaffolding in English-majored Group Interaction in Private College
}

\author{
Shanshan Lang \\ College of Humannities and Sciences of Northeast Normal University, Changchun, Jilin, China, 130117
}

Keywords: peer scaffolding; English-majored group interaction; private college

\begin{abstract}
In the framework of the social-cultural theory, this research analyzes 59 first-year English-majored students from two classes in one private college and finds the features and functions of peer scaffolding in these groups. The research shows that peer scaffolding is common English-majored class in private college, and it has five features and functions, providing vocabulary, correcting wrong expressions, providing opinions, explaining the task, inviting others to engage in the discussion.
\end{abstract}

\section{Introduction}

Social-cultural theory is based on and developed from Vygotsky's children's cognitive development theory. Vygotsky thought, social-cultural environment is the decisive factor for human being to develop from low-level psychological function (such as hearing, smell) to senior psychological function (such as memory, noticing, and the rational thinking). Language is the basic mediating tool in this process of development. Learning takes place through the social interaction between novices (children or learners)) and experts (parents or teachers) (Vygotsky, 1978). Vygotsky pointed out that when children try to solve the problem, two different performances resulted from two different situations: children's existing level of solving the problem demonstrated by independently solving the problem, the other one is the higher level of solving the problem with the aid of adult guidance or peer cooperation. The gap between these two levels constitutes an area called the Zone of Proximal Development. In this dynamic area, learners' mediation with others' help them complete the learning task by changing from potential knowledge and skills into actual development level of learning tasks. The help acquired in the process is termed scaffolding.

The early studies on scaffolding in the language learning classroom suggest that scaffolding appears in conversations between teachers and learners, native speakers and non-native speakers. In recent years, the connotation of the scaffolding has been expanded within the framework of social-cultural theories. Studies have shown that scaffolding do not only appear when experts or teachers provide help to learners with low level of language proficiency, but also when one speaker assists another in performing a function that he or she cannnot perform alone (Ellis, 2003). More and more studies have begun to focus on the interaction of group members in the classroom and peer- scaffolding in interaction (Xu Jinfen, 2016). Storch (2002) studies the interaction of second language learners in a series of tasks. He uses two dimensions, mutuality (that is, the participation degree of the learners' contribution to each other) and equality (that is, the learners to character the degree of control or authority). He reports four patterns of group activities: Expert/Novice pattern, Collaborative pattern, Dominant/Passive pattern and Dominant/Dominant pattern. With more in-depth study, a large number of studies have confirmed that the support provided by the peer has positive effect on the learner's second language development. Donato (1994) makes microcosmic analysis of the three French learners whose native language is English. After recording and analyzing their conversation in preparation for oral task, Donato finds that the learners build support to each other, which is similar to expert guidance. The next day, when these students make the oral statements, they use the forms which they have learnt in preparation conversation. Donato names these support as peer scaffolding. In the process of peer interaction, learners communicate with the target language and provide support to each other to promote their reflection on the language form they use and adjust or modify the language output (Mackey, 2012). Domestic researchers found that 
peer scaffolding is common in college English classroom group conversation, and have summarized seven functions of peer scaffolding in college English classroom interaction through the quantitative study. (Xu Jinfen, 2016).

\section{Research Question and Research Method}

This research focuses on features and functions of peer scaffolding in English-majored class interaction in Private College. Most private college students in China have a relatively lower level of proficiency in the L2 and their class interaction may have their own features and functions. Research subjects are 59 first-year English-majored students from two classes in one private college in Changchun. These 59 students are randomly separated into 12 groups, five students in each group, except one group, which has 4 group members. Textbooks, learning hours, and teaching method are all the same for these two classes.

Four tasks for class interaction are chosen from the textbooks, Communicative English for English-major Learners. These four tasks are: (1) whether three etiquette rules applied both in Chinese and western countries. (2) Choose one suitable box for a lamp. (3) Similarities and differences in appearance and characteristics between Zhang Fei and Guan Yu in Legend of Three Kingdoms. (4) Choose a pair of shoes for a little boy Jimmy. Key words, phrases and sentence patterns for each task have already been given before the discussion.

These four class interactions are recorded by students. They use their own mobile phones, and altogether 48 pieces of interaction utterances are recorded, the average time for each piece is 6 minutes, and then we get 280 minutes pieces of interaction utterances in total. We have identified 38 dialogic discourses containing peer scaffolding, which is illustrated by the dialogic process in which one speaker is assisted by another group member in completing his or her utterance. We also do class observation and make interview with students in order to get more supported data.

\section{Patterns of English-majored Group Interaction in Private College}

Storch (2002) identified four basic patterns in interaction: Collaborative, Dominant/ Dominant, Dominant/ passive and Expert/Novice. This is based on two intersecting dimensions involving mutuality (that is, the level of engagement with each other's contribution) and equality (that is, the degree of control or authority over a task.) collaborative patterns of interaction has the feature of high mutuality and high equality, and all group members actively put forward opinions and participate in negotiation. In Dominant/Dominant patterns of interaction, all group members participate in discussion, but they do not care others' idea and opinion. They state their own opinion and seldom pay attention to others. This pattern has high equality and low mutuality. The feature of Dominant/ Passive is low equality and low mutuality. One member has the authority and he or she controls the task, but this member seldom gives suggestions to any idea. He or she only makes sure all the members participate in the task. In expert/ novice patterns of interaction, an "expert", a key member of the group, organize the interaction and encourage other members to negotiate opinions in the group. This pattern has the feature of high mutuality and low equality. Also Storch reported that the collaborative pattern manifested more instances suggesting evidence of a transfer of knowledge than both the dominant/dominant and the dominant/passive patterns, with the expert/novice group intermediate. (Ellis, 2013)

Based on Storch's report, our research also identifies four patterns of interaction in class in private college. Most peer-scaffolding dialogic discourses are found in collaborative and Expert/Novice patterns of interaction.

\section{Features and Functions of Peer-scaffolding in English-majored Group Interaction in Private College}

After analyzing these 38 dialogic discourses, we classify them into 5 types: providing vocabulary, correcting wrong expressions, providing opinions, explaining the task, inviting others to engage in 
the discussion. The most frequent one is providing vocabulary and correcting wrong expression. These types will be further exemplified and expounded.

\subsection{Providing vocabulary.}

Proving vocabulary is the most frequent function of peer scaffolding in English-majored class interaction in private college. Students in private college have low level of efficiency in second language and low level of lexicon. Though related vocabulary has been given in the pre-task activity, they still encounter vocabulary problems when they have discussion. When one member stops his or her talking due to lack of vocabulary, other group members will assist him or her to go on.

Two discourses demonstrate that the speaker cannot continue their talking and then they use different ways to ask for help from other group members. In one discourse, the speaker stops and uses her body language (thumping on the desk). Others receive the signal and one of them offers the help. The speaker in discourse 2 explicitly asks other group members "how to say..." by using her mother language. B and C give two different answers, "comfortable" and "suitable", which are both appropriate translations of Chinese "He Shi De". Speaker A chooses "suitable" after she thinks of the idea she wants to convey, and then she continues to speak.

These two discourses are selected from two different tasks performed by the same group. This group belongs to collaborative pattern of interaction. Each member actively provides assistance to any speaker in the group. Because of the lower level of proficiency of language, the validity of answer needs to be further discussed, but they negotiate more than other groups and provide more scaffolding.

\subsection{Correcting wrong expressions.}

The function of correcting wrong expressions also frequently appears in the discussion. Correcting wrong expressions mainly includes two aspects: pronunciation and vocabulary. As in the discourse 2, it includes correction of wrong vocabulary. In another discourse, the speaker makes a mistake when she pronounces the sound of "leader", and she is corrected by her group member B. A reads the word again correctly. In this process, speaker A get the correct pronunciation because of her partner's scaffolding. In our data, we do not find any correction in grammar. Xu Jinfen (2016) finds that correction of wrong expressions appears more in vocabulary and pronunciation, but few in grammar.

\subsection{Providing opinions.}

When the speaker temporally cannot think out of any opinions or ideas, group members will try to help her or him to complete. In one discourse, A is describing the appearance of two figures and tries to describe eyes of two figures. B says "phoenix" and A uses this word to finish her statement. This discourse is selected from Expert/Novice patterns of interaction. We also find that in such groups, the group members as Expert not only initiate more turn-taking, they also more likely help other group members complete their speaking and negotiate ideas or opinions which all the group members are not sure.

\subsection{Explaining the task.}

Some group members sometimes may deviate from the requirements of the task due to different level of proficiency of language and cognitive ability etc. other group members will explain the requirement of the task to help them understand the task.

In one discourse, when students discuss whether three given etiquette rules are applied in China and western countries, they are required to give their opinions and state why. In this discourse, A's opinion is "we should use a political or religious topic to get the conversation started." She states her opinion without giving a reason. B asks A to give the reason to support the idea that this etiquette is suitable in China. However, A does not understand the requirement of the task and repeats her opinion again with louder voice. Then $\mathrm{C}$ explains the task to $\mathrm{A}$. In such interaction, it is beneficial to some students like A to understand the requirement of the task and adjust accordingly. It is more effective than communicating with teachers. inviting others to engage in the discussion In 
group discussion, not all the group members can engage in the interaction from the very beginning. The level of engagement with each other's contribution is one dimension in Storch's report. One discourse is found in a typical Expert/Novice pattern. In this five-member group, male students A and $\mathrm{E}$ by turns act as expert to ensure the performance of the task and the negotiation of ideas among all the group members in four tasks. E invites $\mathrm{C}$ to express her opinion by saying "what is your opinion?", because $C$ does not show any ideas since the beginning of the discussion. At the same time, E asks other group members' reaction to C's opinion. When member D does not reacts, A invites D again. The "expert” group members play the key role in group discussion because usually they help inactive members engage in the discussion.

\section{Conclusion}

This research is conducted based on the social-cultural theory, and it focuses on the features and functions of peer scaffolding in English-majored class interaction in Private College. Private college students have their own characteristics in patterns of interaction and features and functions of peer-scaffolding. In the research, we find that peer scaffolding is common in English-majored class interaction. It has the functions of providing vocabulary, correcting wrong expressions, providing opinions, explaining the task, inviting others to engage in the discussion. This research has practical significance to how teachers instruct the group interaction and how to make the effective evaluation criteria on students' performance in the class

\section{Acknowledgement}

Jilin Provincial Association for Higher Education 2017 Higher Education Research General (youth specific) topic. Topic Name: Study on Peer Scaffolding in English-majored Group Interaction in Private College from the Perspective of Social-cultural Theory. Topic Number: JGJX2017D354

\section{References}

[1] Donato, R. 1994. Collective scaffolding in second language learning [A]. In J.Lantolf \& G.Appel (eds.). Vygotskian Approaches to Second Language Research [C]. Norwood: Ablex.

[2] Kayi-Aydar, H. 2013. Scaffolding language learning in an academic ESL classroom [J]. ELT Journal, (3):324-335

[3] Kou Jinnan. 2015. Study on Interaction Patterns in China's College English Classroom [M]. Wuhan: China Publishing Corporation.

[4] Mackey, A. 2012. Input, Interaction, and Corrective Feedback in L2 Learning [M]. Oxford: Oxford University Press.

[5] Rod Ellis, 2013. The Study of Second Language Acquisition (second edition) [M]. Shanghai: Shanghai Foreign Language Education Press.

[6] Storch, N. 2002. Patterns of interaction in ESL pair work [J]. Language Learning, (1): 119-158. 